\title{
Is 3D-Pinter Dangerous? Bioethics as an Instrument of the Humanitarian Expertise of Modern Technologies
}

\section{Farida Nezhmetdinova*}

Philosophy and Law Department, Kazan State Agrarian University, Kazan, Russia

\begin{abstract}
Today one can state that our civilization faced the whole complex of global problems: problem of a preservation of peace on Earth, ecology, a food problem, overpopulation, overcoming of poverty of a majority of mankind, a problem of health and quality of life. The greatest popularity in their resolving is won by technological approaches: bio-nano-infokogno. We become eyewitnesses or direct participants of the breakthrough scientific achievements that allow changing the fundamental bases of life - at the level of a live and artificial matter, and even their synthesis. In this article we study a possible danger of unreasoned application of modern NBIK (nano-bio-info-kogno) of technologies to live systems (human being and nature) and suggest positive experience of bioethics as humanitarian expertise.
\end{abstract}

\section{Introduction}

Many scientists connect the sixth wave of technological development with development of convergent technologies. The new long cycle, supposed to start in 2011-2015, will be based on use of the latest nano - bio - and information and communication technologies (NBIK) [1]. Thus the number of spheres with which start begins include, along with electrotechnical, aviation and nuclear branches, health care and others, the agriculture based on application of achievements of molecular biology and genetic engineering.

A question of limits of the mankind's future becomes sharper with development of technologies. This situation relatively is new to it - it is formed at the end of the XX century (rather even at a turn of centuries) - and that is its force and risks. Force - that the person has time for pronouncement of the decision on how to deal with it, time to develop methods of prevention of undesirable consequences, time for improvement - situation has less chances to develop to the critical forms imperceptibly. Risks - in "draft to novel" and global challenges of world economy.

Without suspecting danger, treating the events as to the next procedure of development of medicines or products, household items and leisure which are intended for human life improvement of quality, we risk not to notice fundamental differences of the events from everything that we happened to test earlier (or that we had to test on ourselves). Just to take last case with 3-D printer. At the beginning of May, 2013 American Cody Wilson (Cody Wilson) developed and printed on 3D-printer the operating gun "The Liberator" that use standard bullet of 38th caliber $(9 \mathrm{~mm})$. After successful tests of the weapon, drawings were laid out in a free access in the Internet - for two days they were downloaded by more than 100 thousand people! It caused negative reaction of the authorities. Sharp criticism followed right after the publication of drawings - in particular, Senator Steve Israel urged to forbid using 3D-printers for production of the weapon. Critics point to high availability of such weapon and its low-visibility for security check machines. The US authorities already on May 13, 2013 officially demanded from the Defense Distributed company (founded by Wilson) to remove drawings of the plastic gun for $3 \mathrm{D}$ - printers from its website. Though the company fulfilled the requirement, the copies were already on many servers, including Pirate Bay. It is difficult to imagine further succession of events and after the entire printer is a quite peace tool [2].

The question was never raised in this way - as possible change of the fundamental bases of the nature and the human being. From this point of view, the thing is not in ethical principles used during genetic researches or creation of GMOs products, it isn't "god-like" or getting the unlimited "bio-power" - all the matter is that we have "opened a window" to absolutely new look of "material viability" [3]. Whether live organisms "healthy" for the person and other living beings or will they turn in causative agents of diseases, whether they will improve evolutionarily developed genotype of the person or on the contrary will lead to deviations from it. There are still no answers to such questions.

All this, fantastic, at first sight, opportunities, generate many fears concerning probabilistic transition of modern researches to an uncontrollable phase. Respectively there is a need for the special mechanism of control and regulation [4]. As a result it is necessary to develop social regulators in the form of ethical rules and the regulations which can somehow block negative consequences and risks of implementing NBIK-technologies. It seems that the bioethics as the scientific concept and practice can be one of the main tools here.

\section{Methods and Methodology}

Today, when NBIK-technologies are aimed at the organization of new type of materiality or "material viability", the problem of a choice of system of counting for designing of new system of values looks very actual [5]. To comprehend need of humanitarian examination from the side of bioethics, it is necessary to analyze conceptual approaches and the points of view to those technological hazards, which arise in various scopes of applying of NBIK-technologies.

Speaking about technological decisions, rare modern researcher or scientist won't miss opportunity to sound alarm and to call for vigilance. Well-known American sociologist J. Nesbit, analyzing

*Corresponding author: Farida Nezhmetdinova, Head of Philosophy and Law department, Kazan State Agrarian University, Tatarstan Republic, 420015 , Kazan, K. Marks st-65, Russia, Tel: +7 843 5674608; +79196217070; E-mail: nadgmi@mail.ru www.kazgau.ru

Received June 07, 2013; Accepted July 27, 2013; Published August 07, 2013

Citation: Nezhmetdinova F (2013) Is 3D-Pinter Dangerous? Bioethics as an Instrument of the Humanitarian Expertise of Modern Technologies. J Clin Res Bioeth 4: 153. doi:10.4172/2155-9627.1000153

Copyright: (c) 2013 Nezhmetdinova F. This is an open-access article distributed under the terms of the Creative Commons Attribution License, which permits unrestricted use, distribution, and reproduction in any medium, provided the original author and source are credited. 
characteristic features of modern society (e.g. American) calls it "the Zone of Poisoned Technology" [6].

The research by J.Naisbitt of change of sense of the concept "technology" in the American encyclopedic literature is a point of interest in this regard. In 1967 the word "technology" meant "object, a material and the physical processes separated from human beings". In 1987 it is added with "relationship of technology with life, society and environment, society and environment", in 1998 the term "consequences" is added. The last means that technologies can't be neutral. As a result, to balance "high technology" one needs high humanity: feelings of compassion, recognition of the rights of other person, ability to put all efforts to protect justice, ability to understand the primitive force of life and death [7-12]. The place of bioethics in this context is not last at all - it performs as the humanitarian examination, capable to accept the technology keeping our humanity, and to reject technology, encroaching on it.

Widespread introduction of modern biomedical technologies in the second half of the XX century in medical practice in the conditions of developing democracy led to emergence of such social phenomenon as Bioethics [13-21]. At the moment the bioethics on the one hand is recognized scientific area of the interdisciplinary knowledge with its subject - the assessment and a choice of moral criteria of the relation to live (definition of the author - F.N.). On the other hand it is approved by the world community social practice of ethical regulation of scientific researches and, first of all, clinical researches and medical activity [2225].

In the majority of foreign and domestic researches the bioethics and biomedical ethics are considered as synonymous, if not the identical. The following opinion is widespread: "The term "bioethics" as it was formed in modern culture, has only indirect relation in some private sections to problems of the ethical relation to animals, plants and wildlife in general. Most likely, it defines the space of problems, studied by medical professional ethics. Therefore some researchers instead of the term "bioethics" use the term "modern medical ethics", "biomedical ethics", just "medical ethics", meaning its present stage" [25]. It automatically moved bioethics only to the sphere of professional medical activity, maximum - to ethics of scientific researches. "First of all, one tries to identify bioethics with biomedical ethics, limiting its contents to ethical problems of the relations "the doctor - the patient" [16]. As a result, it is possible to claim that a medical and biomedical perspective, undoubtedly, are the central and substantial core of all bioethical perspective in general. At the same time, as W.Th. Reich emphasizes, it is caused by the fact that anthropocentrism is a dominating way of thinking and outlook in bioethics, and "genetically" the bioethics is the closest one to medical ethics [5,26]. The bioethics in its American variant comes now exactly from ethics of medicine and biomedicine. This subject is still dominating - one just can study the catalog of library of Georgetown University (The Bioethics Research Library at Georgetown University) [2].

Meanwhile, today it is necessary to see the bioethics as a certain answer to various calls of scientific and technical progress, and not just medicine. It also not to a lesser extent corresponds to the general, for all human civilization cultural and social changes, global problems of the present. For example, we can take the food problem, which is that to provide people with food, it is necessary to increase production of the food by $2 \%$ annually. You can not achieve that by usual methods that is why today hard works in the field of chromosomal and genetic engineering are conducted [3].
The point of view of W.Th. Reich, the editor-in-chief of the Encyclopedia of Bioethics, could be the methodological basis of such thesis. He defines bioethics as a "systematic studying of area of morals - including moral views, decisions, behavior and policy - in sciences about life and the medical care, using variety of ethical methodologies in interdisciplinary space". Further he specifies that publishers consider bioethics as the discipline which is beyond medical ethics. It unites in herself: moral interpretation of medical and scientific views on health of the population, environment, and ethics of society and protection of animals" [16] (author italics - F.N.). The article "Bioethics" (written by Daniel Callahan) in the encyclopedia deserves special attention. D.Callahan is one of those scientists who stood at the origins of bioethics both as concepts and as sciences [17]. He defined bioethics as science, "which is a product of the biomedical achievements relating to environment and social sciences" [17]. He also emphasizes that the bioethics represents the further transformation of medical ethics and while primary center of bioethics is the medicine and health care, possibilities of bioethics cover a set of areas and the disciplines which have been widely grouped under a heading "sciences about life". "Bioethics" came to direct people to a wide field of moral problems of the life covering usually medicine, biology, environment, the population and social sciences [5]. In other words, the bioethics is not only anthropocentric, but is also biocentric.

The range of issues covered today by bioethics, strikes with the variety, but all of them are united by a priority of such universal values as life, health, wellbeing, justice. Other characteristic feature of bioethics is its interdisciplinary character, when representatives of medicine, law sciences, technologies philosophy, biology different religions take equal part in bioethical discussions.

It is really hard to define borders of life and death, who has the right to choose limits of his/her existence - the professional or the simple person, what moral and legal status of an "in vitro" embryo, whether "the substitute motherhood" is justified, how does the person accept genetic designing and possible cloning of her/himself, whether it is moral to use a human being or an animal as object of clinical researches, whether it is possible "to sort" the person on "spare parts" and to arrange public competitions on their placement in view of total "deficiency", whether genetically modified products of agriculture and nanotechnology in medicine are safe for the person, whether medicosocial resources, etc. are fairly distributed.

The last quarter of the 20th century and the beginning of the 21st generated such specific phenomenon, which the German sociologist Ulrich Beck defined as "other modernist style" or "risk society" [27]. Thus, as marks out Russian philosopher P.D.Tishchenko, specifics of a social context of various technologies has historically uncertain character when science and society, social phenomena and the person constantly test themselves in self-identification attempts and by that constantly change, becoming others [28]. These changes generate "constellations of opportunities" which give person a choice of some vector of development from a set of possible ways. In these conditions this choice is irreversible and most often can't be unambiguously counted. And here, fairly, in my opinion, change of sense and the concept of term "risk" is emphasized - firstly, it goes from category of personal space to global level. Secondly, if last century the risk was considered as result of insufficient development of technologies and scientific knowledge, today the risk arises where redundancy of technological and scientific progress [3] is shown.

Today many philosophers, sociologists note a phenomenon of acceleration of changes in the social life, caused by accelerating of 
scientific and technical progress which, as E.Toffler defined, become "future shock" [29] and determine it "ecotechnological development" [29]. It is possible to agree completely with his opinion on the fact that "change acceleration considerably changes balance between new and familiar situations. Increasing rates of changes compel us to cope not simply with faster stream, but all with a large number of situations to which the previous personal experience doesn't approach" [29].

There are a number of the factors understanding which we can approach to awareness of increasing relevance of humanitarian examination in the form of bioethics. It is important to define:

1. Expansion of a subject field of bioethics as interdisciplinary knowledge area, in which development the most various scientific disciplines take part: biology, medicine, philosophy, sociology, law, study of religions. Today the subject of bioethics deals with fundamental bases of life of the person and the nature, borders of live and artificial, the right to intervention in live systems and their change, their transformation into object of purchase and sale as element base (genes, bodies), and results of changes. Increasing role of NBIK- technologies in providing health and worthy quality of human life, in biodiversity preservation, ensuring food security and ecological purity is obvious. But also it is obvious that there is high degree of potential and real danger of their implementation. The prevention of their use without preliminary expert humanitarian examination actualizes need of development of bioethics as a scientific discipline, school of sciences and practice $[1,30,31]$.

2. Becoming the creator of NBIK-technologies, humankind gets real opportunity to reconstruct biospace, socio-space, its own biogenetic nature, to create new "materiality" and the cultural environment. All this promotes development of "biopower" and not only in that sense which M. Foucault put in this concept, but also in regard to all live systems of the planet Earth [3]. Under the increasing pressure of global problems and competition our planet turns into peculiar "laboratory", in which more and more risky experiments are carried out. The special place in this system is taken by a complex of the reasons connected with modern scientific strategy, with the fourth global scientific revolution during which the new post-nonclassical science is born. For this science it is common that implementation of comprehensive research programs (where experts of various fields of knowledge take part) occurs in the same time. During study of "human-sized" objects the search for truth is connected with definition of strategy and the possible directions of transformation of such object. This is connected with humanistic values when the researcher should solve a number of problems of ethical character and to define borders of possible intervention in it [32]. On this particular "field" there is an expansion of a subject field of bioethics and process of generation of its new forms: nanobioethics, cyberbioethics and others. All this demands additional judgment.

3. Rapid development of biology and medicine, significant growth in number of biomedical researches and number of their participants, introduction in medical practice of new diagnostic and medical technologies generates many new problems concerning observance of the rights and respect of dignity of the person, prevention of discrimination on medicobiological and especially genetic bases, ensuring justice in access to achievements of biomedical science. Special value is gained by questions of ethical and legal regulation of application of high medical technologies, pharmacology and genetics. Today the bioethics in medicine is generally guided by the pathological theory of medicine: sharp conditions, chronic disease and death. At the same time, the medicine theory, based on $4 \mathrm{P}=$ predictive (probabilistic medical history on the basis of analyses and researches, first of all genetic), personalized, preventive (preventive or precautionary), participatory (Lee Hood, 2007, Institute for Systems Biology, Seattle) is getting popular [33]. It will demand to revise standards of good practice, ethics of "doctor-patient" relationship and many other things.

4. The food safety is ensured by the development of biotechnologies on the main food, distributions of the food products received from genetically modified plants with use of genetically modified microorganisms and microorganisms that have genetically modified analogs. Genetically modified cultures in the world occupy today the space of 8,1 million hectares, and sales annually grow for $20 \%$. Receiving genetically modified organisms, as a result - increase the crops of cultural plants and efficiency of agricultural animals, becomes more and more widespread solution of the problem of the food in the world and way of reduction of prices of food. At the same time use of GMO can represent potential risk for health and development of the person. Many genes used at creation of GMO, earlier never were a part of food. Inconsistent results and non-sufficient theoretical basis warm up disputes. Such contradictions revealed not only existence of a wide range of the opinions among the UN member-states on regional and interstate levels, but also heterogeneity of regulatory bases and the principles of an assessment of advantages and the risks connected with GMO food. Besides, many developing countries aren't able to create the specialized structures necessary for effective regulation of questions, connected with GMO food. As a result, the demand of experience of bioethics will increase its social value as well, and new forms will appear. One of these forms could be taken by agrobioethics, understood as the mechanism of social control and regulation of new "material viability" in bio-economy [3].

5. An important subject of the discussions concerning genetically modified organisms is the intellectual property rights. Problems of equal access to genetic resources, equitable distribution of received advantage at global level and avoidance of emergence of monopolies exist both for GMO of food, and for other areas of use of gene technologies. On the fifteenth of April, 2013 the Supreme Court of the USA heard positions of Association of Molecular Pathology and the Myriad Genetics Company on case that can answer a question: "Under what conditions, if they exist at all, it is possible to patent human genes?" Kevin Emerson Collins, the employee of Justice Department, the expert in the field of patent business and the professor of law of Washington University, considers that to predict an outcome of this case is extremely difficult [34].

6. Realization of modern architecture of science can essentially change the universal use of organic forms of life for different types of the labor activity covering space from environmentally friendly productions to the sphere of leisure and culture. It is already possible to see it in "science art" - the new direction of the modern art which relies on post-biology: robotics, artificial life, bio - and genetic engineering. Today it is difficult even to estimate approximately the consequences which will be caused by reproduction of the artificially created live. One even doesn't know what are the relations between artificial and natural live organisms going to be [28].

7. Modern sports also became the noticeable public phenomenon in $20^{\text {th }}$ and $21^{\text {st }}$ centuries. It is dynamically developing in a context of modern social, economic and political processes. But it seems that there comes a new doping era in the world of sports. The future is genetic engineering, almost all experts agree. Doctor Theodor 
Fridmann, the main adviser of WADA (World Anti-Doping Agency), emphasized that use of a so-called genetic dope to increase sporting achievements is inevitable [34]. The question, of course, is that how genetic technologies can be used to improve results of athletes and that such manipulation are not sports but become only achievements of biotechnology? This question and many others remain open and demand efforts of many experts from all over the world. The dope, whatever it is, is not the same as cloning. Any country can forbid or allow experiments on cloning of the person. It is, generally, the internal question of the state. But when business concerns an elite sport, representation of the countries at the Olympic Games, the World Cups and Europe, in this case the consent of all sports officials, scientists, doctors, philosophers and theologians is required.

\section{Results}

It is obvious that in process of development of modern architecture of science - convergence of NBIK-technologies, large-scale introduction of post-biological technologies, there is an increasing need of mechanisms of social control - so, relevance of bioethics will increase as well. Expansion of a field of a discourse of bioethics, possible extrapolation of its estimated regulating role and experience of its use as the instrument of humanitarian examination on ecology spheres, introduction of biotechnologies in agriculture, professional sports, etc., becomes more and more demanded. The bioethics has to develop as theoretical discipline and as a number of applied directions. It could be medical bioethics, agrobioethics, ecobioethics, nanobioethics, cyberbioethics, bioethics of sports of high achievements, bioethics in a context: problems of biosafety, bioeconomy, biopower.

Taking into account of the abovementioned, it is obviously possible to draw the following conclusions:

1. Bioethics, being from the birth an interdisciplinary area of knowledge, is close to social philosophy, as one of results of the global social changes concerning the limit bases of the person, the nature and society. It speaks about existence of the ontological status of the bioethics determined by change of fundamental bases of human being and the nature. Certainly, it proves that bioethics is a philosophical discipline.

2. Subject of bioethics as new scientific discipline is the assessment and a choice of moral criteria to live, and as social technology - definition of the principles and criteria of the moral relation to live [3].

3. The bioethics represents a new type of scientific knowledge; it is "internal optics" of modern technologies which relies on procedures and methods of "advancing experience". When at the same time there is a theoretical analysis and an increment of new knowledge, public discussion and practical adoption of the moral decision.

4. Studying place and role of bioethics in the conditions of the global changes, its social and regulatory status becomes obvious; it is urged to prevent their negative consequences, not to allow the irreversible result of techno-power, gained by mankind with modern technologies. This status is operating through the mechanism of humanitarian examination.

5. There is a real and possible change of fundamental bases of the person when to bio-, socio- and psycho- bases the techno- is added. Soon we will argue on the nature of human being, using these new coordinates, it will generate new theories and practices.

6. Scientific pictures of the world are changing, influenced by global scientific revolutions, but ideas of the person and its natural bases changed much more slowly. Certain "lag" of knowledge of the person from knowledge of the nature was observed. And only today there is a chance, when modern technologies "reached" the "live" person, to minimize this distance and to create essentially other scientific picture of the world.

7. The bioethics becomes demanded in the form of responsible decision-making practice [35-39], because of its axiological character and available experience (a method of "advancing experience", work of Ethical Committee, etc.).

8. Mission of bioethics does not consist of alarmist motives, but of propaedeutics and dialogue, search for compromises among multiprofessional, scientific and business communities.

9. New "material viability" creates not only chimeras, but also new empirical experience of feelings and a rational reflection.

Creating "something another", using our methods and approaches we show tendency to dominate, will to the power - they are in our "explorative" nature. For this reason connection of bioethics with knowledge on the one hand, and introduction of modern NBIKtechnologies with another, can become that "internal optics" needed, which at last will allow us to look critically on ourselves [40-43]. At the same time it is impossible to allow that the bioethics becomes a leader of anti-intellectual tradition - though temptation is high. The special type of vigilance is necessary - it isn't reduced to groundless rejection of all new - on the contrary, it includes understanding or "experience" of dangers, caused by modern technologies.

\section{References}

1. Bakshtanovsky V.I. V, Somogonov Yu (2007) Applied ethics: idea, bases, and way of existenceVI. Bakshtanovsky Yu.V. Somogonov.//Philosophy questions. â€" 2007.-â-9. â€.

2. The Bioethics Research Library at Georgetown University

3. Nezhmetdinova F (2013) Global challenges and globalization of bioethics Croat Med J 54: 83-85.

4. Potter VR (1988) Global Bioethics: Building on the Leopold Legacy. Michigan State University Press, USA.

5. Nezhmetdinova FT and Islanova NN (1998) Law and medicine: bioethical bases - Kazan: Publishing house, Press house, Russia.

6. John Nesbit (2005) High technology, deep humanity.Technologies and ou searches of sense / John Nesbit with the assistance of Nana Nesbit and Douglas Fillips - Moscow: Nuclear heating plant: TransitBook.

7. Arthur W B (2009) The Nature of Technology. What it is and How it Evolves, Free Press, ISBN 978-1-4165-4405-4400.

8. Drucker P F (2011) Technology, Management and Society, pp. 108-119, Harvard Business Review Press, ISBN 978-1-4221-3161-9.

9. Kelly K (2010) What Technology Wants, Penguin Books, ISBN 978-0-67002215-1,USA.

10. Kurzweil R (2005) The Singularity is Near: When Humans Transcend Biology, Penguin Books,ISBN 0-670-03384-7, USA.

11. Lightman A,Sarewitz D, Desser C (2003) Living with the Genie, Essays on Technology and the Human Quest for Human Mastery, Island Press, ISBN I-55963-419-7, Washington, USA.

12. Schweber SS (2000) In the Shadow of the Bomb: Oppenheimer, Bethe and the Moral Responsibility of Scientist, Princeton University Press, ISBN 0-691 04989-0,USA.

13. Potter, Van Rensselaer (1971) Bioethics: Bridge to the future / Potter, Van Rensselaer. - Englewood Cliffs, Prentice-Hall, USA.

14. Glenn Hartelius (1995) Encyclopedia of bioethics Reich, Island press Washington, USA 
Citation: Nezhmetdinova F (2013) Is 3D-Pinter Dangerous? Bioethics as an Instrument of the Humanitarian Expertise of Modern Technologies. J Clin Res Bioeth 4: 153. doi:10.4172/2155-9627.1000153

Page 5 of 5

15. Hellegers, Andre (1971) Bioethics center formed, Chemical and engineering news.

16. Reich WT (1994) The word "bioethics": its birth and the legacies of those who shaped it. Kennedy Inst Ethics J 4: 319-335.

17. Daniel Callahan. Bioethics (1995) Encyclopedia of bioethics, Reich, 247-248.

18. Max Charlsworth (1993) Bioethics in liberal society. / Max Charlsworth. Cambridge Uiversity Press.

19. H Tristan Engelhard (1994) The Foundation of Bioethics. / H. Tristan Engelhard, Jr. - Oxford University Press.

20. Tomas A Shannon (1997) An introduction to bioethics, NJ Paulist Press, Newyork, UK.

21. RM Hare (1993) Essays on Bioethics, Clarendon Press. Oxford, USA.

22. Arras JD, Fenton EM (2009) Bioethics \& human rights: access to health-related goods. Hastings Cent Rep 39: 27-38.

23. Brunetto (2011) Global Bioethics, Perspective for Human Survival, InTech Janeza Trdine 9, 51000 Rijeka, Croatia.

24. Bioethics in the 21st Century, Edited by Abraham Rudnick (2011) InTech Janeza Trdine, Rijeka, Croatia.

25. Beauchamp TL, Childress JF (2009) Principles of Biomedical Ethics, Oxford University Press, USA.

26. Nezhmetdinova FT (2006) Defense of the rights and safety of human life in a context of achievements of modern biomedical technologies.

27. Beck U (2000) Risk society, on a way to another modern.

28. Tishchenko P D (2001) Bio - power during an era of biotechnologies.

29. Toffler E. Future Shock (2008) Philosophy.
30. Vodopyanova E (2007) Other science: order innovative society.

31. Shaykhudinov RG (2007) Modern technologies of the power.

32. Nezhmetdinova FT(2004) An urgency of humanitarian examination in a role of $\hat{A}$ «public reasonÂ» and as factor of preservation human potential. /Prospects of modern development: Materials of the Russia scientific conference, section of interdisciplinary researches Â«Public and private spaces of modern.

33. Lee Hood (2007) Institute for Systems Biology.

34. Monsanto sued small famers to protect seed patents.

35. G. Jonas (2004) Responsibility principle, Ethics experience for a technological civilization.

36. VA Sadovnichy (2005) Knowledge and wisdom in the being globalized world, the report at Plenary session of the IV Russian philosophical congress "Philosophy and the civilization future.

37. Potter VR (1971) â€œBioethics: Bridge to the Futureâ€, Prentice-Hall, Englewood.

38. Rudnick A (2007) Processes and pitfalls of dialogical bioethics. Health Care Analysis.

39. F. Fukuyama (2004) Our post-human future. Consequences biotechnological revolution, JSC AST Publishing House: JSC Lyuks.

40. Kovalchuk M V (2011) Convergence of sciences and technologies â€“" break in future.//The Russian nanotechnologies.

41. Philosophy of biomedical researches: ethos of sciences of the beginning of the third millennium. â€" Moscow: Institute of the person of the Russian Academy of Sciences.

42. Gun drawings for 3D- The printer loaded 100 thousand times.

43. 2013 List of Prohibited Substances and Methods.
This article was originally published in a special issue, Case Reports in Bioethics handled by Editor. Azetsop J, Department of Medical Ethics, South

Africa 